Article

\title{
Active Control of Sound Transmission through Orthogonally Rib Stiffened Double-Panel Structure: Mechanism Analysis
}

\author{
Xiyue Ma *, Kean Chen and Jian Xu \\ School of Marine Science and Technology, Northwestern Polytechnical University, Xi'an 710072, China \\ * Correspondence: xiyuema@nwpu.edu.cn
}

Received: 13 July 2019; Accepted: 6 August 2019; Published: 10 August 2019

Featured Application: Active double-panel sound insulation structure can be applied as potential noise control technic in aviation and navigation to actively control the low frequency sound transmission into the cabin.

\begin{abstract}
Physical mechanisms of active control of sound transmission through orthogonally two ribs stiffened double-panel structure are investigated. This is the continued work of the single rib stiffened case. For the orthogonally two ribs stiffened case, four different cluster mode groups can be coupled with each other, due to the interlaced coupling effects of the horizontal and vertical ribs. One cavity mode can couple with and transmit sound energy to any type of base plate mode of the radiating ribbed plate. Consequently, the main differences of the control mechanism, when compared with the single ribbed case, lie in two aspects. One is that a novel mechanism appears. That is, suppressing and rearranging the cavity modes simultaneously achieves the suppression of the base plate modes. The other is that rearrangement of the cavity modes to rearrange the base plate modes for achieving sound radiation cancellation almost does not appear. The reason is that all types of cavity mode can couple with any one of the base plate modes due to the coupling effects of the two ribs. There is only a need to rearrange several important cavity modes to achieve suppressing the base plate mode of the radiating ribbed plate.
\end{abstract}

Keywords: orthogonally two ribs stiffened double-panel structure; sound transmission; active control; physical mechanisms

\section{Introduction}

The rib stiffened double-panel structure is the most common form of bulkhead structure used in aviation and navigation [1]. Such structure has predominant sound insulation performance in mid and high frequency range. It can effectively isolate noise, induced by uncertain dynamic loads or turbulent flow loads, transmitting into the cabin. However, the level of sound insulation declines remarkably in the low frequency range. Excessive heavy damping materials are required if the passive noise control approach is applied, which, however, do not always achieve remarkable effects. In order to further effectively improve low frequency sound insulation performance, an active control approach may then be applied [2].

Much research work has been carried out on the unribbed double-panel structure [3-7], and little attention [2] has been given to the ribbed case. In order to fill these theoretical gaps, Ma [8] presents an analytical investigation on the physical mechanism of active control of sound transmission through a single rib stiffened double-panel system, using the cavity control approach. Only a single rib stiffened case is involved in this research to simplify the model. Such an approach allows the authors to 
pay close attention to distinctly explore the elementary physical nature of active control. However, the double-layer cabin walls are usually the classical orthogonally n-ribbed plate. In order to improve the engineering relevance of the analytical research, this study further presents a more practical structure which refers to the orthogonally two ribs stiffened double-panel system. Hence, this research is continued from the work in Ref. [8]. The aim of this paper is to further explore the active control mechanisms of such a structure, which may support engineering application of this technique in the future. The orthogonal ribbed case is only concerned with one horizontal and one vertical rib. Although such a structure is not in accord with the engineering applications, it seems to be more practical. The purpose of this is to simplify the investigation. Understanding the physical nature of active control in orthogonal ribbed cases may provide better understanding of complicated mechanisms involved in an orthogonal n-ribbed case [9].

Many techniques [10-15] have been proposed to accurately predict free vibration of the ribbed plate. Some other techniques $[2,16]$ have been also applied to model complicated double-panel structures composed of rib stiffened plates. These contributions deepen the comprehending of the vibration characteristics of the rib stiffened plate and rule of sound energy transmission through these structures, which offers assistance for noise and vibration control engineering. One new modeling approach proposed recently is the modal expansion method $[1,8,17]$, which can clearly reflect the coupling effects between the rib and plate. Therefore, Ma [18] applies this model to investigate the active control of noise radiation from the single rib stiffened plate. Some original mechanisms which differ from these of the unribbed plate case have been obtained. Ma [8] further applies modal expansion and vibro-acoustic coupling methods to model the single rib stiffened double-panel structure. It provides a good understanding of the rule of sound energy transmission between the cavity and radiating ribbed plate, and also the original mechanisms of active control triggered by the coupling effects of the rib. As a continuous work, the model for the orthogonally two ribs stiffened case in this research is also established using the method involved in Ref. [8].

Compared with the unribbed double-panel system [4-6,19-21], the physical mechanism of active control of noise transmission presents additional prominent differences for the single ribbed case. Due to the remarkable free vibration characteristic for the ribbed plate (the modes, which have the same modal index along the rib direction, can couple with each other [18]), the differences present as the following two aspects [8]. One of them involves suppressing the mechanism. More cavity modes will be excited even on resonant frequencies of the ribbed plate, due to the coupling effects of the ribs. Only these cavity modes that play an important role in the energy transmission process need to be suppressed. The second aspect is that the cavity modes are firstly rearranged, and then the energy contributions from different cavity modes to the same base plate mode cancel each other. The suppression and rearrangement work together in this case. Further concerned with the orthogonally two ribs stiffened case, the sound energy transmission rule and active control process will be more complicated. As well as the aforementioned mechanisms, excess novel phenomena will arise. Due to the interlaced coupling effects of the horizontal and vertical ribs, the four mode groups of the base plate of the radiating ribbed plate can couple with each other. Therefore, any one cavity mode can couple with all types of the base plate mode. A mutual energy transmission between them is also observed. Based on these specific coupling relations, the energy transmission rule in the orthogonally two ribs stiffened double-panel structure will be analyzed first in this research. Then, the mechanism of active control will be renewed by analyzing the change of the rule of energy transmission between the cavity modes and radiated base plate modes in a controlled condition.

The remainder of this paper is organized as follows. The theoretical modeling approach is described in Section 2. An in-depth investigation on the physical mechanism of active control is presented in Section 3. Conclusions are summarized in Section 4. 


\section{Theoretical Modeling Approach}

The control system is schematically shown in Figure 1. The upper ribbed plate A and lower ribbed plate $\mathrm{B}$ are orthogonally rib stiffened plates with one rib along the horizontal and another along the vertical directions. The rib parallel with $x$-axis is the horizontal rib, and the one parallel with $y$-axis is the vertical rib. For the upper ribbed plate $A$, the vertical and horizontal ribs are located at $x=x_{a}$ and $y=y_{a}$, respectively. The lower ribbed plate $\mathrm{B}$ has the vertical rib located at $x=x_{b}$ and the horizontal rib located at $y=y_{b}$. The boundary conditions of the base plate and the ribs are all clamped. The remaining parts of the system (the rigid walls of four sides, and the control source) are basically the same as that of the single ribbed case [8]. The upper plate is excited by primary excitation of an oblique incident plane wave. A controllable point source is applied to control the sound field of the cavity, which indirectly suppresses the sound transmission.
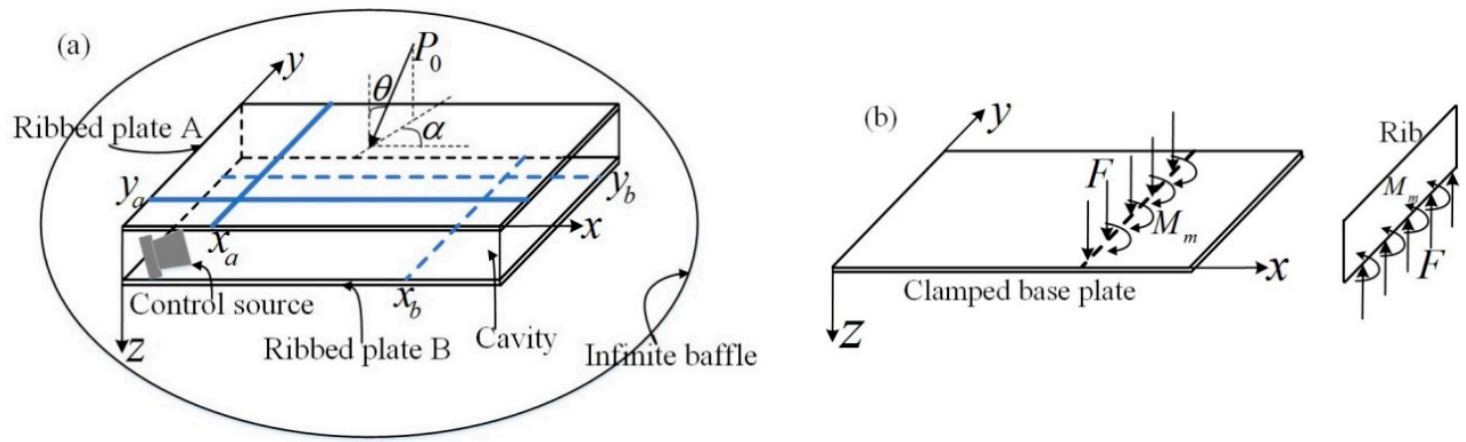

Figure 1. Sketch of the model. (a) Active sound insulation double-panel system. (b) Sketch of coupling effects in connection line between the base plate and the rib.

The beam/plate interface is modeled as a nonslip line connection, in which a pair of coupling force $F$ and moment $M_{m}$ is considered to simulate the beam/plate coupling effects, as shown in Figure $1 \mathrm{~b}$. Under the excitation of an oblique incident plane wave [22] and the coupling effects of the ribs, the equations that the transverse bending displacements of the base plate $\mathrm{A}$ and $\mathrm{B}\left(w_{a}, w_{b}\right)$ satisfy are similar to that of the single ribbed case [8]. However, another coupling force and moment induced by the horizontal rib should be added into the right side of the equations [8]. Taking the ribbed plate A as an example, the equation that the bending displacements $w_{a}$ of the base plate A satisfies can be expressed as:

$$
\begin{gathered}
D_{a} \nabla^{4} w_{a}+\rho_{a} h_{a} \frac{\partial^{2} w_{a}}{\partial t^{2}}=f_{p}(\mathbf{r}, t)+F_{a, v} \delta\left(x-x_{a}\right)+M_{m, a, v} \delta^{\prime}\left(x-x_{a}\right) \\
+F_{a, h} \delta\left(y-y_{a}\right)+M_{m, a, h} \delta^{\prime}\left(y-y_{a}\right)-p(\mathbf{r}, t)
\end{gathered}
$$

where $\nabla^{4}$ denotes the Laplacian, $D_{a}$ are the flexural rigidity of the base plates, $D_{a}=E_{a} h_{a}{ }^{3} / 12\left(1-\sigma_{a}^{2}\right)$. $E_{a}, h_{a}$ and $\sigma_{a}$ are the Young's modulus, thickness and Poisson's ratio of the base plate, respectively. $\rho_{a}$ is the density the base plates. $F_{a, v}$ and $M_{m, a, v}$ are the coupling force and moment for the vertical rib. $F_{a, h}$ and $M_{m, a, h}$ are the coupling force and moment for the horizontal rib. $f_{p}(\mathbf{r}, t)$ is the primary excitation of the oblique incident plane wave, and $\mathbf{r}=(x, y, z)$ is the random spatial position. $p(\mathbf{r}, t)$ is the sound pressure in the air cavity.

The sound pressure $p(\mathbf{r}, t)$ in the cavity also satisfies the inhomogeneous wave equation when a point source with controllable amplitude $Q_{s}$ is introduced, which is presented in Ref. [8]. By solving the coupled equations of the system, the modal amplitude vectors of the base plate A and B $\left(\mathbf{q}_{a}, \mathbf{q}_{b}\right)$, and the cavity $(\mathbf{P})$ can be calculated. Then, the systematic response can be obtained. It is noteworthy that variable $Q_{s}$ remains undetermined in these expressions of the modal amplitude. The system response before control can be obtained when $Q_{s, a}(\omega)=0$. For the controlled condition, the response continually depends on the variable $Q_{s, a}(\omega)$. The optimal amplitude $Q_{s, a, o p t}(\omega)$ can be obtained by minimizing the objective function of the radiated power of the ribbed plate $\mathrm{B}$. The detailed derivation 
process is similar to Ref. [8], where the coupling force and moment induced by the horizontal rib is added into the relative vectors and matrices.

\section{Mechanism Analysis for Active Control}

\subsection{Model Parameters Assignment and Model Validation}

The geometrical parameters and material properties of the model are listed in Table 1 . The structure damping is ignored in the modeling. Thus, a constant internal loss factor $\eta=0.01$ is introduced into the complex Young's modulus as $E(1+i \eta)$ to make the simulation results more practical. The ribs are modeled as uniform beam elements with a rectangular cross section. All of the ribs have the same geometrical size of the rectangular cross section. The plane wave has an amplitude of $P_{0}=1 \mathrm{~Pa}$, and is an incident at $\theta=\pi / 4$ and $\alpha=\pi / 4$. The controllable point source is located at $\left(0.1 l_{x}, 0.1 l_{y}, 0.1 \mathrm{~h}\right)$ in the cavity, in order to excite most of the low frequency modes of the cavity (up to $500 \mathrm{~Hz}$ ). Generally speaking, the convergence of the model can be achieved in the low frequency range by increasing the number of modes, which can guarantee the accuracy of the solution. Once the solution is convergent at a given frequency, it is also convergent for all frequencies lower than that. For the upper frequency $(500 \mathrm{~Hz})$ considered in this research, the numbers of the modes for each subsystem, i.e., the base plate, the rib, and the cavity, are determined as $M=N=10, N=10$ and $L=40$. The increment of the radiated sound power of the ribbed plate $B$ is less than $1 \mathrm{~dB}$ when the numbers of the mode of the subsystem increase from the case of $\mathrm{N} 2$ to N1, which guarantees the accuracy of the model. The variation trend of the radiated sound power of the ribbed plate B with the numbers of the modes gradually increasing is shown in Table 2 .

Table 1. The geometrical parameters and material properties of the system.

\begin{tabular}{cccc}
\hline Geometrical Parameters & Value & Material Properties & Value \\
\hline $\begin{array}{c}\text { The length and width of the base } \\
\text { plate A and B }\end{array}$ & $\begin{array}{c}l_{x}=1.2 \mathrm{~m} \\
l_{y}=0.84 \mathrm{~m}\end{array}$ & $\begin{array}{c}\text { The material of the } \\
\text { base plates and the ribs }\end{array}$ & aluminum \\
\hline $\begin{array}{c}\text { The thickness of the base } \\
\text { plate A and B }\end{array}$ & $\begin{array}{c}h_{a}=0.006 \mathrm{~m} \\
h_{b}=0.008 \mathrm{~m}\end{array}$ & $\begin{array}{c}\text { The density of } \\
\text { aluminum }\end{array}$ & $\rho=2790 \mathrm{~kg} / \mathrm{m}^{3}$ \\
\hline $\begin{array}{c}\text { The locations of the vertical and } \\
\text { horizontal ribs for ribbed plate A }\end{array}$ & $\begin{array}{c}x_{a}=0.3 \mathrm{~m} \\
y_{a}=0.21 \mathrm{~m}\end{array}$ & $\begin{array}{c}\text { The Young's modulus } \\
\text { of aluminum }\end{array}$ & $E=7.2 \times 10^{10} \mathrm{~N} / \mathrm{m}^{2}$ \\
\hline $\begin{array}{c}\text { The locations of the vertical and } \\
\text { horizontal ribs for ribbed plate B }\end{array}$ & $\begin{array}{c}x_{b}=0.9 \mathrm{~m} \\
y_{b}=0.63 \mathrm{~m}\end{array}$ & $\begin{array}{c}\text { The Poisson's ratio of } \\
\text { aluminum }\end{array}$ & $\sigma=0.34$ \\
\hline $\begin{array}{c}\text { The size of the rectangular cross } \\
\text { section of the rib (wide } \times \text { high) }\end{array}$ & $A=0.003 \times 0.04 \mathrm{~m}^{2}$ & $\begin{array}{c}\text { The density of air } \\
\text { The depth of cavity }\end{array}$ & $\rho_{0}=1.21 \mathrm{~kg} / \mathrm{m}^{3}$ \\
\hline The location of the control source & $\left(0.1 l_{x}, 0.1 l_{y}, 0.1 \mathrm{~h}\right)$ & $\begin{array}{c}\text { The damping ratio of } \\
\text { acoustical mode }\end{array}$ & $\boldsymbol{c}_{0}=344 \mathrm{~m} / \mathrm{s}$ \\
\hline
\end{tabular}

Table 2. The variation trend of the radiated power of the ribbed plate B (at $500 \mathrm{~Hz}$ ).

\begin{tabular}{ccc}
\hline Case & The Number of the Modes & The Radiated Power of the Ribbed Plate B \\
\hline N1 & $M=N=10, N=10, L=40$ & $45.8 \mathrm{~dB}$ \\
N2 & $M=N=9, N=9, L=30$ & $45.2 \mathrm{~dB}$ \\
N3 & $M=N=8, N=8, L=20$ & $44.8 \mathrm{~dB}$ \\
N4 & $M=N=6, N=6, L=20$ & $43.5 \mathrm{~dB}$ \\
N5 & $M=N=5, N=5, L=20$ & $37.6 \mathrm{~dB}$ \\
N6 & $M=N=4, N=4, L=20$ & $29.1 \mathrm{~dB}$ \\
\hline
\end{tabular}


For validating the accuracy of the theoretical model, the double-panel structure is also modeled by the Finite Element Software (FES, COMSOL (5.2a, COMSOL lnc., Stockholm, Sweden)). The upper and the lower ribbed plate, and the cavity are modeled using the Volume element. The model is divided by the "Free tetrahedral mesh". The element size of the mesh in COMSOL is subdivided into nine grades. The grade of normal is chosen in this study. The detailed elemental size parameters are as follows, maximum element size: 0.12 , minimum element size: 0.0216 , maximum element growth rate: 1.5, curvature factor: 0.6 , and resolution of narrow regions: 0.5 . In this case, the total numbers of the finite element mesh are 103,085 domain elements, 28,035 boundary elements and 1838 edge elements. A point force with amplitude being $1 \mathrm{~N}$ is added at $(1.0,0.64)$ on the ribbed plate $\mathrm{A}$. The displacement on the monitoring point $(0.3,0.21)$ on the ribbed plate $B$ is calculated. It is also resolved by the analytical model, as shown in Figure 2. The results obtained by these two methods agree well, which validates the accuracy of the theoretical model. The finite element model is illustrated in Figure 3. Besides, the beam/plate interface is considered as a nonslip line connection in the theoretical model. Yet, in the numerical model, the interface is a rectangular area, and the coupling effects between the rib and plate are slightly stronger than in the analytical model. Therefore, the resonant frequencies of the ribbed plate calculated by COMSOL are slightly higher than those calculated through the analytical approach (seen in Figure 2). Furthermore, the difference for the rib-stiffness control mode will be little larger than that of the plate-stiffness control mode [15]. The ribs are located at or close to the anti-nodal locations of the mode for the rib-stiffness control modes, in which case the coupling effects of the ribs will have a more prominent effect. This explains why the difference is remarkable for the first several modes of the ribbed plate (seen in Table 3).

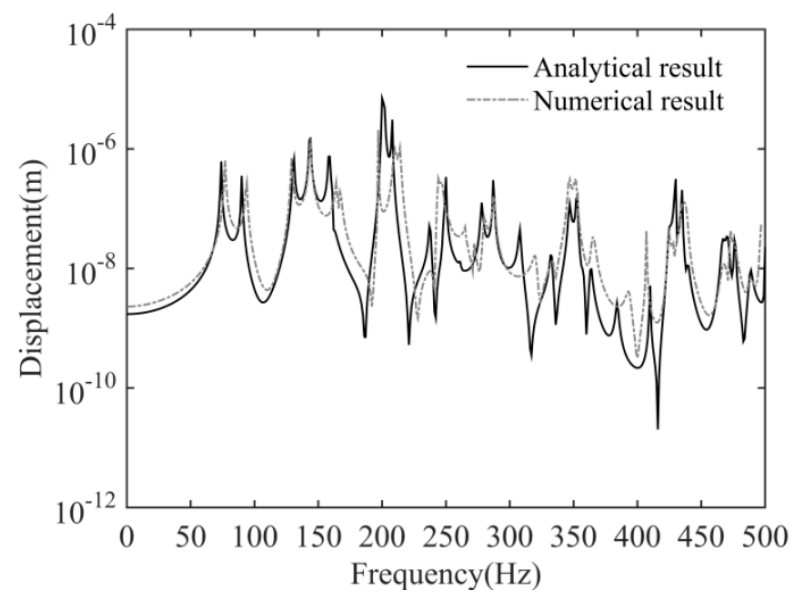

Figure 2. The displacement on the monitoring point of the ribbed plate B, calculated by analytical and numerical methods.

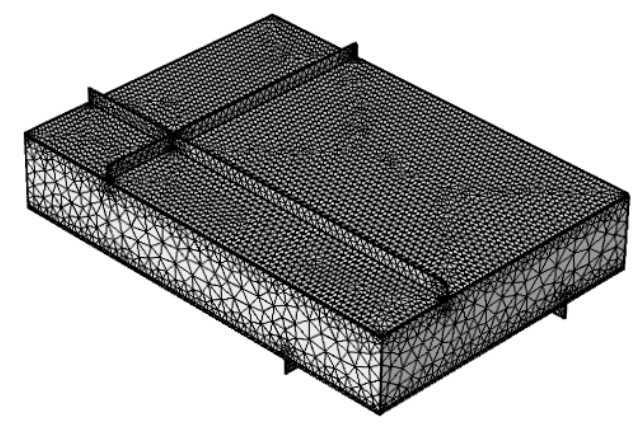

Figure 3. The finite element model of the rib stiffened double-panel structure. 
Table 3. The resonant frequencies of the ribbed plate A and B below $500 \mathrm{~Hz}$.

\begin{tabular}{|c|c|c|c|c|c|c|c|c|c|c|c|c|c|c|c|}
\hline \multirow{2}{*}{\multicolumn{2}{|c|}{$\begin{array}{c}\text { Category } \\
\text { Modal Sequence }\end{array}$}} & \multicolumn{14}{|c|}{ Resonant Frequency (Hz) } \\
\hline & & 1 & 2 & 3 & 4 & 5 & 6 & 7 & 8 & 9 & 10 & 11 & 12 & 13 & 14 \\
\hline \multirow{2}{*}{ Ribbed plate A } & $\begin{array}{l}\text { Analytical } \\
\text { results }\end{array}$ & 73 & 132 & 161 & 201 & 248 & 261 & 278 & 347 & 358 & 384 & 430 & 439 & 471 & 489 \\
\hline & COMSOL & 76 & 135 & 165 & 204 & 250 & 264 & 280 & 347 & 361 & 383 & 430 & 439 & 472 & 493 \\
\hline \multirow{2}{*}{ Ribbed plate B } & $\begin{array}{l}\text { Analytical } \\
\text { results }\end{array}$ & 90 & 158 & 203 & 238 & 308 & 333 & 364 & 425 & 467 & 473 & & & & \\
\hline & COMSOL & 92 & 161 & 206 & 239 & 310 & 333 & 365 & 419 & 467 & 477 & & & & \\
\hline
\end{tabular}

\subsection{The Resonant Characteristics of the Ribbed Plate}

The mode shapes and resonant frequencies of the orthogonally ribbed plate can be obtained by resolving the eigenvalues and eigenvectors of the homogeneous equations of Equations (14) and (15) in Ref. [8]. The theoretically calculated resonant frequencies below $500 \mathrm{~Hz}$ and also the results obtained by FEM method are listed in Table 3. The resonant frequencies of the cavity below $500 \mathrm{~Hz}$ are also shown in Table 4 to assist with the analysis.

Table 4. The resonant frequencies of the cavity below $500 \mathrm{~Hz}$.

\begin{tabular}{cccccccccccc}
\hline & \multicolumn{10}{c}{ Resonant Frequency (Hz) } \\
\hline \multirow{2}{*}{ Modal index } & 1 & 2 & 3 & 4 & 5 & 6 & 7 & 8 & 9 & 10 & 11 \\
\cline { 2 - 31 } & $(0,0,0)$ & $(1,0,0)$ & $(0,1,0)$ & $(1,1,0)$ & $(2,0,0)$ & $(2,1,0)$ & $(0,2,0)$ & $(3,0,0)$ & $(1,2,0)$ & $(3,1,0)$ & $(2,2,0)$ \\
\hline Frequency & 0 & 143 & 205 & 250 & 287 & 352 & 410 & 430 & 434 & 476 & 500 \\
\hline
\end{tabular}

The mode shapes of the first ten modes of the ribbed plate B are plotted in Figure 4. The formation of the resonant mode of the orthogonally two ribs stiffened plate is similar to that of the single ribbed case. For the single ribbed plate, the modes of the base plate, of which the modal index along the rib direction are identical, couple with each other and have mutual energy transmission due to the coupling effects of the rib [8]. The overall vibrational superposition of this set of modes forms the resonant mode of the ribbed plate. For the orthogonally two ribs stiffened case, additional coupling effects induced by the horizontal rib are introduced. The coupling effects are produced in the same manner that the base plate modes, of which the modal index along the horizontal rib direction are identical, can couple with each other. Simultaneously taking the coupling effects of the horizontal and vertical ribs into considerations, it can be predicted that all base plate modes can couple with each other. One mode can always couple with any other mode through a complex coupling relation and energy transmission process. Therefore, the set of modes for constituting the resonant mode of the orthogonally ribbed plate is supposed to contain all four types of the base plate mode. In this set, one or two modes with high modal amplitudes dominate. The first twenty base plate modes are also shown in Table 5 for aiding the analysis.

Table 5. The first twenty modes of the base plate.

\begin{tabular}{ccccccccccccccc}
\hline \multicolumn{110}{c}{ Modal Index } \\
\hline 1 & 2 & 3 & 4 & 5 & 6 & 7 & 8 & 9 & 10 & 11 & 12 & 13 & 14 & 15 \\
\hline$(1,1)$ & $(2,1)$ & $(1,2)$ & $(3,1)$ & $(2,2)$ & $(3,2)$ & $(4,1)$ & $(1,3)$ & $(2,3)$ & $(4,2)$ & $(5,1)$ & $(3,3)$ & $(5,2)$ & $(4,3)$ & $(1,4)$ \\
\hline 16 & 17 & 18 & 19 & 20 & & & & & & & & & & \\
\hline$(6,1)$ & $(2,4)$ & $(3,4)$ & $(5,3)$ & $(6,2)$ & 110 & \\
\hline
\end{tabular}



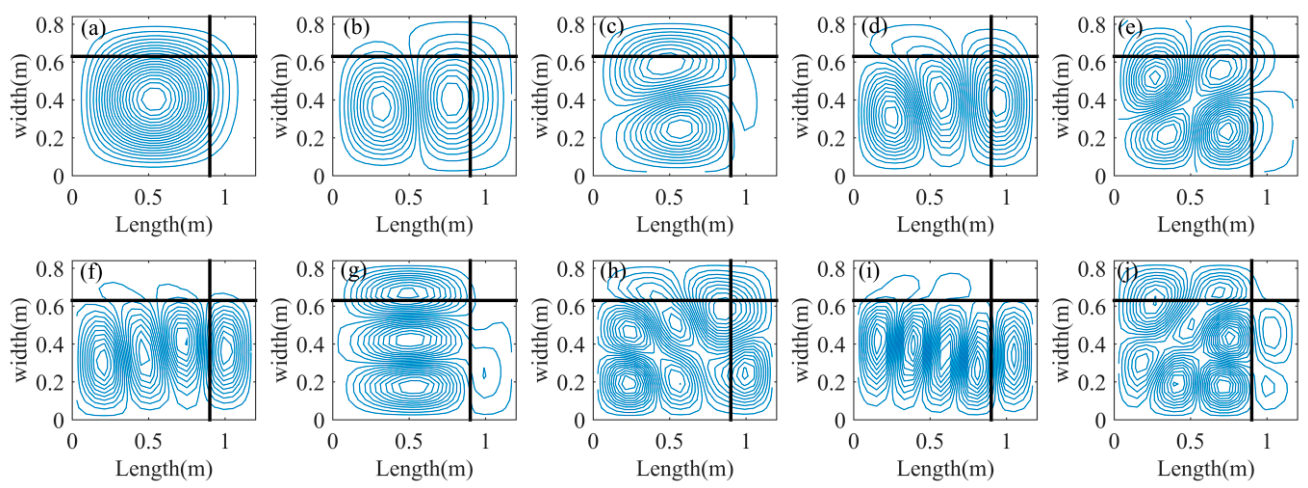

Figure 4. The mode shape of the modes of the ribbed plate B ((a-e) for the first five modes, and $(\mathbf{f}-\mathbf{j})$, for the modes from the sixth to tenth).

\subsection{Control Results}

The radiated sound power of the ribbed plate B before and after control is plotted in Figure 5a as a function of frequency. The sound radiation reduction (or transmission loss improvement) is remarkable in almost all of the low frequency range, especially at resonant peaks. There are some special peaks at which the control is invalid. The constitution of the resonant mode for the orthogonally ribbed plate is more complicated than that of the single ribbed case. The control authority of single point source may be limited for controlling these modes. The noise reduction on off-resonant frequencies is considerable only in these narrow bands centered by the resonant peaks. Active sound insulation (ASI), $A S I=10 \times \lg \left[W_{b, b e f} /(1 E-12)\right]-10 \times \lg \left[W_{b, a f t} /(1 E-12)\right]$, where $W_{b, b e f}$ and $W_{b, a f t}$ are the radiated sound power of the ribbed plate B before and after control) is calculated for the single rib and two ribs stiffened case, as shown in Figure 5b. ASI for the single ribbed case is slightly higher than that of the two ribs stiffened case. The declined performance is due to the complicated coupling relations between the ribbed plate and cavity in this case.
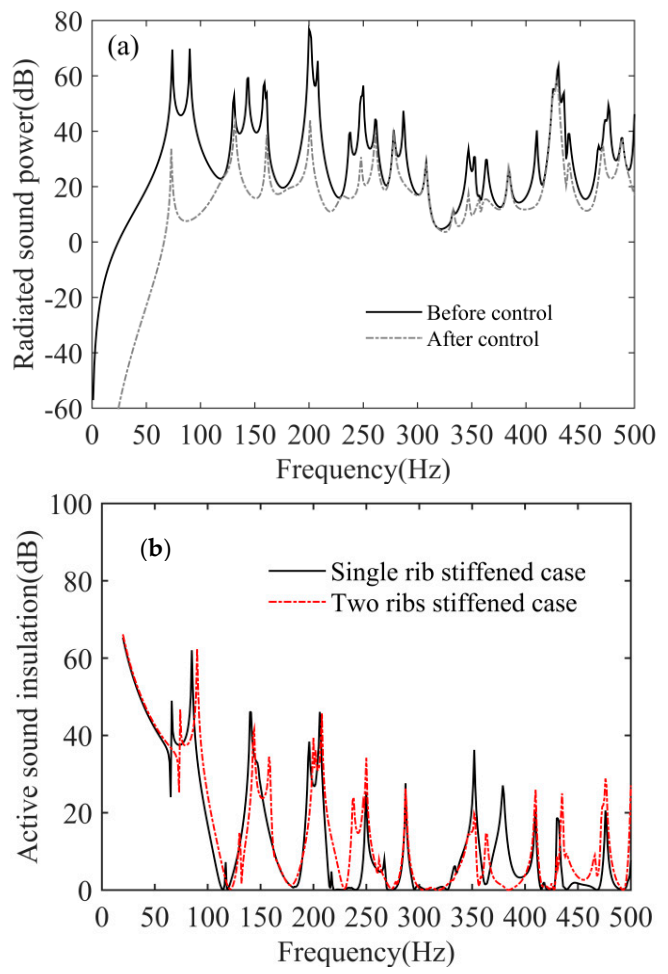

Figure 5. The radiated sound power of the ribbed plate B before and after control. (a) For the orthogonally ribbed case. (b) Comparing the control effect between the single ribbed case and the two ribs stiffened case. 


\subsection{Physical Mechanism Analysis}

For the single ribbed double-panel system, one cavity mode can couple with and transmit energy to a set of modes of the radiating base plate. Most of the modes in this set have no geometrical coupling relations with this cavity mode. Essentially, they set up relevance with it through the coupling effects of the rib. This in turn means that the energy contained in one base plate mode is supposed to be transmitted from different cavity modes. Accordingly, the prominent mechanism of active control supresses the base plate modes by rearranging the cavity modes. The suppression and rearrangement mechanisms work together. Due to the complicated coupling relations between the ribbed plate and cavity, the control mechanisms for the orthogonally two ribs stiffened case differ from those of the single ribbed case, and also present more interesting phenomena. Detailed analysis is carried out in a similar way to that of the single ribbed case when the exciting frequency is chosen as the resonant and off-resonant frequencies.

\section{(a) On the resonant frequency of cavity}

It is assumed that the exciting frequency is $f=352 \mathrm{~Hz}$, where the 6 th $(2,1,0)$ cavity mode resonates. The modal amplitudes of the first twenty cavity modes and base plate B modes before and after control are shown in Figure 6. Many modes of the base plate B are excited. Only $(1,2)$ mode is excited directly by this cavity mode due to their geometrical coupling relations. Other plate modes are all excited by the $(1,2)$ mode in an indirect way through the coupling effects of the vertical and horizontal ribs. For instance, the $(2,2)$ mode is excited indirectly by the coupling effects of the vertical rib. The $(4,1)$ mode should be excited by the $(1,1)$ mode through the coupling effects of the vertical rib, where the prerequisite is that the $(1,1)$ mode should firstly be excited by the $(1,2)$ mode through the coupling effects of the horizontal rib. The $(1,3)$ mode is excited indirectly by the coupling effects of the horizontal rib. Then, it further excites the $(2,3)$ mode by the coupling effects of the vertical rib.

In general, one cavity mode can couple with all four types of the base plate modes in direct or indirect ways, due to the coupling effects of the orthogonal two ribs. The coupling relations and energy transmission among the four types of base plate modes are complicated and even difficult to be traced. However, the energy contained in each excited base plate mode comes from one cavity mode. Once the cavity mode is suppressed, all the excited base plate modes are suppressed accordingly, as can be seen in Figure 6b. Only one cavity mode is excited at the resonant frequencies of the cavity, showing that the modal suppression mechanism works effectively. This is formally analogous with that in the single ribbed case. The only difference is that more base plate modes, i.e., all four types of the base plate mode, have participated in the control process.
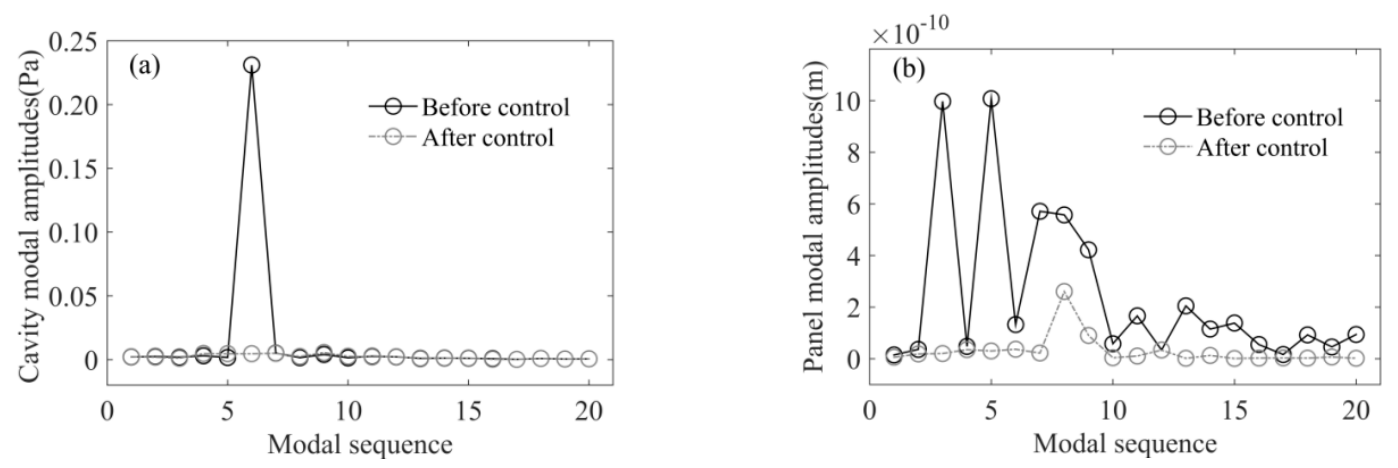

Figure 6. Modal amplitudes of the first twenty modes before and after control ( $f=352 \mathrm{~Hz})$. (a) Cavity modes. (b) Base plate B modes.

\section{(b) On the resonant frequency of the ribbed plate $\mathrm{A}$}

Three cases, where the exciting frequency is successively fixed at $f=248 \mathrm{~Hz}$ (Case 1), $f=161 \mathrm{~Hz}$ (Case 2), and $f=439 \mathrm{~Hz}$ (Case 3 ) are considered. The 1st, 3rd, and 12th modes are resonant, respectively. 
Figure 7 shows the modal amplitudes of the cavity mode and base plate B mode before and after control in these cases. The control mechanism at $248 \mathrm{~Hz}$ is also the cavity mode suppression, as shown in Figure 7 (Case 1), which is similar to that of the cavity resonant frequency.

Many cavity modes are excited in Cases 2 and 3. Due to the coupling effects of the orthogonal two ribs, the particular coupling relations and energy transmission rule from each excited cavity mode to these excited base plate modes may be difficult to be traced. Even for the cavity and plate mode pair that satisfies the geometrical coupling relation (expressed in the coupling coefficient $\mathbf{L}_{b}\left(i_{\text {plate-mode }}, j_{\text {cavity-mode }}\right) \neq 0$ ), the part of energy contained in the plate mode contributed from this cavity mode is supposed to be transmitted both in direct and indirect ways. In general, each cavity mode can couple with and transmit energy to any one of the base plate modes. The mechanism of active control can be interpreted by analyzing the variation of energy contributions of different cavity modes to each base plate mode in controlled conditions. According to Equation (15) in Ref. [8], the modal amplitudes of the base plate B can be expressed as:

$$
\mathbf{q}_{b}=\left(\mathbf{K}_{b}-\omega^{2} \mathbf{M}_{b}\right)^{-1}\left(\mathbf{L}_{b}\right)^{\mathrm{T}} \mathbf{P}=\mathbf{Z} \mathbf{P}
$$

where $\mathbf{Z}=\left(\mathbf{K}_{b}-\omega^{2} \mathbf{M}_{b}\right)^{-1}\left(\mathbf{L}_{b}\right)^{\mathrm{T}}$ is defined as the transfer impedance matrix. For the energy contained in each base plate mode, its contribution from each cavity mode can be calculated using Equation (2). These contributions can be represented by the value of $z(i, j) P(i)$ which are expressed as a complex value (amplitude [phase]) to illustrate their superposition or cancellation effects. In Case 2, the energy contained in the first, second and fourth base plate B modes, which are contributed from the first five cavity modes, are listed in Table 6. In Case 3, the energy contained in the third to eighth modes of the base plate B that are contributed from the first ten modes of the cavity are also listed in Table 6 .

In Case 2, it is noteworthy that the energy contained in these excited base plate modes are all mainly transmitted from the second cavity mode $(1,0,0)$, and only a little from the $(0,1,0)$ mode. Although the $(1,0,0)$ mode is weakly excited with small amplitude, as shown in Figure $7 \mathrm{c}$, its energy contribution is predominant due to the direct strongly coupling effects between this mode and the $(2,1)$ mode, seen in Table 6 (Case 2). Whereas, although the 3rd $(0,1,0)$ cavity mode is strongly excited, its energy contribution is insignificant. The reason is that the energy from this cavity mode to these base plate modes is transmitted through complicated indirect coupling path. In a controlled condition, the $(1,0,0)$ cavity mode is firstly suppressed to a certain degree. Then, the quantity of its energy contribution to the base plate modes is considerable with that of the $(0,1,0)$ mode. But, the phase of the $(1,0,0)$ mode is just adjusted to have a $180^{\circ}$ phase difference (opposite phase) with that of the $(0,1,0)$ mode. The energy contributions from these two cavity modes further cancel each other to achieve the suppression of the modes of the base plate $B$. The cavity modal suppression and rearrangement work together to achieve the suppression of the modes of the base plate B, as shown in Figure $7 \mathrm{~d}$ and Table 6 (Case 2). Besides, the control process for different base plate modes is nearly the same. The energy contained in these plate modes is almost completely transmitted from the same energy source of a group of excited cavity modes. Hence, the control effects will be delivered successively to all of these excited base plate modes, as shown in Table 6 (Case 2).

The situation in Case 3 is basically the same as that in Case 2 . The energy contained in these intensively excited $(1,2),(3,1),(2,2),(3,2),(4,1)$, and $(1,3)$ plate modes is mainly transmitted from the $(3,0,0)$ and $(1,2,0)$ cavity modes. The phase difference of the two parts of energy contribution from these two cavity modes is small before control. Hence, the two parts of energy contribution to base plate modes approach complete superposition. Since the $(1,2,0)$ mode is intensively excited with a highest modal amplitude, the energy contribution from this mode is more than that from the $(3,0,0)$ mode. The $(1,2,0)$ mode is firstly suppressed to a certain degree in a controlled condition. Then, its energy contribution is considerable with that of the $(3,0,0)$ mode, but its phase is simultaneously adjusted to be opposite to the energy contribution from the $(3,0,0)$ mode. Then, the two parts of energy contribution further cancel each other, which finally results in the suppression of these base plate modes, as shown 
in Figure 7 (Case 3) and Table 6 (Case 3). Note that the $(0,1,0),(1,1,0),(2,1,0)$ and $(3,1,0)$ cavity modes can also transmit energy to the $(2,2),(3,2)$ and $(1,2)$ base plate modes with a substantial quantity. However, the energy contributions from the $(0,1,0),(1,1,0)$ modes are just out of phase with those of the $(2,1,0)$ and $(3,1,0)$ modes. The total contribution of these four cavity modes dissipates each other. Accordingly, less additional control effect is needed to suppress the energy transmission from these cavity modes.

The mechanism in the single ribbed case only involves Case 1. The mechanism discussed in case 2 and 3 is a new phenomenon that is not observable in the single ribbed case. The complicated coupling relations and energy transmission rule between the cavity modes and base plate modes in the orthogonally ribbed case generates this novel phenomenon. Although the analysis is carried out only at several specific frequencies, the rule of control is of universality at other frequencies as well.
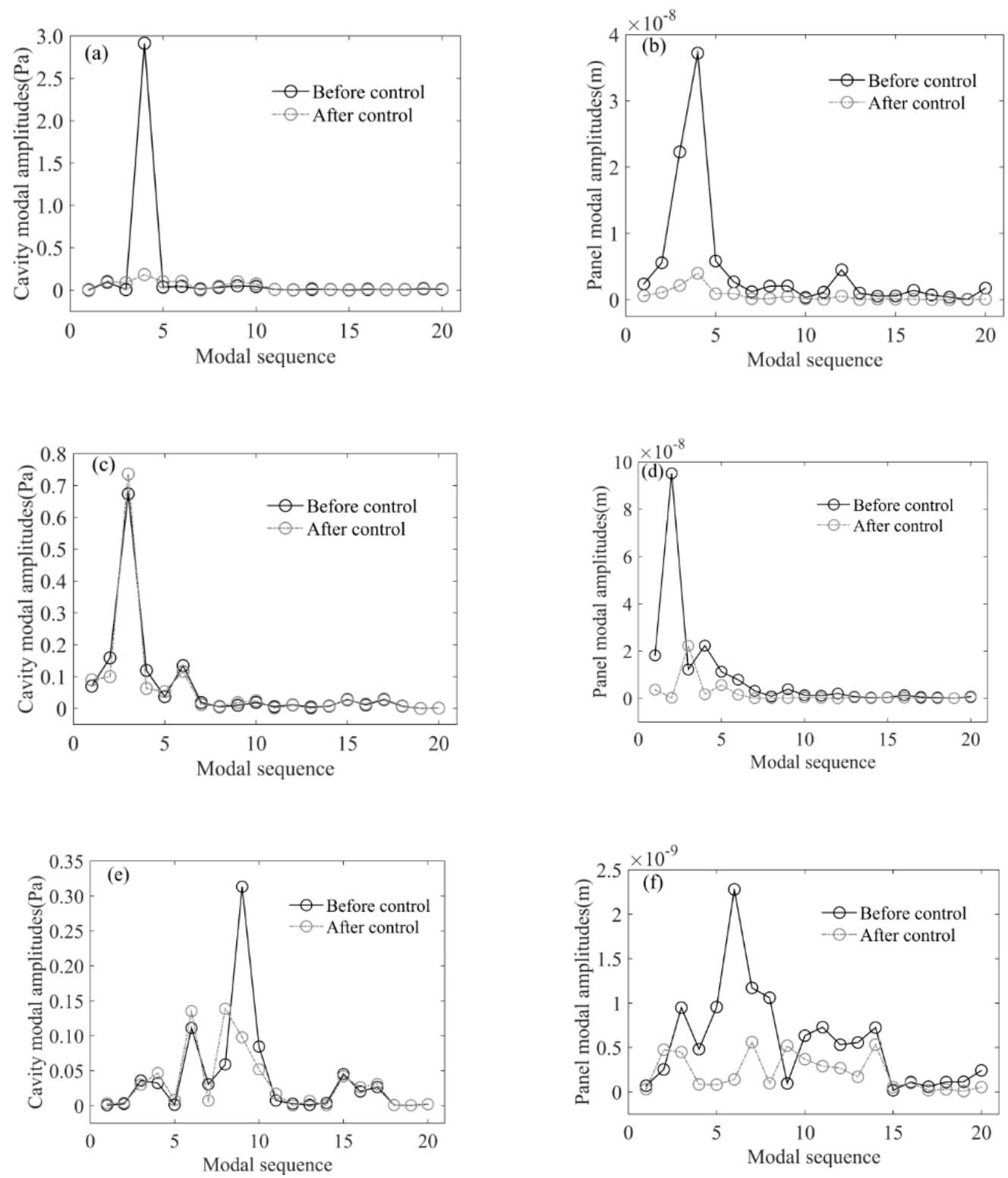

Figure 7. Modal amplitudes of the first twenty modes before and after control when $f=248 \mathrm{~Hz}$ (Case 1), $f=161 \mathrm{~Hz}$ (Case 2), and $f=439 \mathrm{~Hz}$ (Case 3). (a,c,e) (a) Cavity modes for Case 1, (c) Cavity modes for Case 2, (e) Cavity modes for Case 3. (b,d,f) (b) Base plate B modes for Case 1, (d) Base plate B modes for Case 2, (f) Base plate B modes for Case 3. 
Table 6. The energy contributions of the cavity modes to the base plate B modes.

\begin{tabular}{|c|c|c|c|c|c|c|c|c|c|c|c|}
\hline & & \multicolumn{10}{|c|}{ The Energy Contributions from Cavity Modes $(z(i, j) P(i)$, Unit: m) } \\
\hline \multirow{2}{*}{\multicolumn{2}{|c|}{ Cavity modes }} & 1 & 2 & 3 & 4 & 5 & 6 & 7 & 8 & 9 & 10 \\
\hline & & $(0,0,0)$ & $(1,0,0)$ & $(0,1,0)$ & $(1,1,0)$ & $(2,0,0)$ & $(2,1,0)$ & $(0,2,0)$ & $(3,0,0)$ & $(1,2,0)$ & $(3,1,0)$ \\
\hline \multicolumn{12}{|c|}{ Case 2} \\
\hline \multirow{2}{*}{$(1,1)$} & Before control & $\begin{array}{c}0.04 \times 10^{-7} \\
{\left[40^{\circ}\right]}\end{array}$ & $\begin{array}{c}0.10 \times 10^{-7} \\
{\left[57^{\circ}\right]}\end{array}$ & $\begin{array}{c}0.05 \times 10^{-7} \\
{\left[48^{\circ}\right]}\end{array}$ & $\begin{array}{c}0.01 \times 10^{-7} \\
{\left[-133^{\circ}\right]}\end{array}$ & $\begin{array}{c}0.01 \times 10^{-7} \\
{\left[52^{\circ}\right]}\end{array}$ & & & & & \\
\hline & After control & $\begin{array}{c}0.45 \times 10^{-8} \\
{\left[37^{\circ}\right]}\end{array}$ & $\begin{array}{c}0.65 \times 10^{-8} \\
{\left[-135^{\circ}\right]}\end{array}$ & $\begin{array}{c}0.50 \times 10^{-8} \\
{\left[45^{\circ}\right]}\end{array}$ & $\begin{array}{c}0.04 \times 10^{-8} \\
{\left[-139^{\circ}\right]}\end{array}$ & $\begin{array}{c}0.22 \times 10^{-8} \\
{\left[48^{\circ}\right]}\end{array}$ & & & & & \\
\hline \multirow[b]{2}{*}{$(2,1)$} & Before control & $\begin{array}{c}0.04 \times 10^{-7} \\
{\left[-134^{\circ}\right]}\end{array}$ & $\begin{array}{c}0.62 \times 10^{-7} \\
{\left[-123^{\circ}\right]}\end{array}$ & $\begin{array}{c}0.33 \times 10^{-7} \\
{\left[-134^{\circ}\right]}\end{array}$ & $\begin{array}{c}0.05 \times 10^{-7} \\
{\left[46^{\circ}\right]}\end{array}$ & $\begin{array}{c}0.04 \times 10^{-7} \\
{\left[-124^{\circ}\right]}\end{array}$ & & & & & \\
\hline & After control & $\begin{array}{c}0.05 \times 10^{-7} \\
{\left[-136^{\circ}\right]}\end{array}$ & $\begin{array}{c}0.39 \times 10^{-7} \\
{\left[44^{\circ}\right]}\end{array}$ & $\begin{array}{c}0.36 \times 10^{-7} \\
{\left[-136^{\circ}\right]}\end{array}$ & $\begin{array}{c}0.03 \times 10^{-7} \\
{\left[39^{\circ}\right]}\end{array}$ & $\begin{array}{c}0.06 \times 10^{-7} \\
{\left[-128^{\circ}\right]}\end{array}$ & & & & & \\
\hline \multirow{2}{*}{$(3,1)$} & Before control & $\begin{array}{c}0.02 \times 10^{-7} \\
{\left[-138^{\circ}\right]}\end{array}$ & $\begin{array}{c}0.14 \times 10^{-7} \\
{\left[-123^{\circ}\right]}\end{array}$ & $\begin{array}{c}0.08 \times 10^{-7} \\
{\left[-134^{\circ}\right]}\end{array}$ & $\begin{array}{c}0.01 \times 10^{-7} \\
{\left[46^{\circ}\right]}\end{array}$ & $\begin{array}{c}0.01 \times 10^{-7} \\
{\left[-120^{\circ}\right]}\end{array}$ & & & & & \\
\hline & After control & $\begin{array}{c}0.24 \times 10^{-8} \\
{\left[-141^{\circ}\right]}\end{array}$ & $\begin{array}{c}0.85 \times 10^{-8} \\
{\left[43^{\circ}\right]}\end{array}$ & $\begin{array}{c}0.85 \times 10^{-8} \\
{\left[-137^{\circ}\right]}\end{array}$ & $\begin{array}{c}0.05 \times 10^{-8} \\
{\left[40^{\circ}\right]}\end{array}$ & $\begin{array}{c}0.08 \times 10^{-8} \\
{\left[-124^{\circ}\right]}\end{array}$ & & & & & \\
\hline \multicolumn{12}{|c|}{ Case 3} \\
\hline \multirow{2}{*}{$(1,2)$} & Before control & $\begin{array}{c}0.01 \times 10^{-10} \\
{\left[127^{\circ}\right]}\end{array}$ & $\begin{array}{c}0.02 \times 10^{-10} \\
{\left[-118^{\circ}\right]}\end{array}$ & $\begin{array}{c}0.22 \times 10^{-9} \\
{\left[-65^{\circ}\right]}\end{array}$ & $\begin{array}{c}0.04 \times 10^{-9} \\
{\left[-70^{\circ}\right]}\end{array}$ & $\begin{array}{c}0.02 \times 10^{-10} \\
{\left[28^{\circ}\right]}\end{array}$ & $\begin{array}{c}0.02 \times 10^{-9} \\
{\left[-160^{\circ}\right]}\end{array}$ & $\begin{array}{c}0.02 \times 10^{-9} \\
{\left[-75^{\circ}\right]}\end{array}$ & $\begin{array}{c}0.09 \times 10^{-9} \\
{\left[-99^{\circ}\right]}\end{array}$ & $\begin{array}{c}0.48 \times 10^{-9} \\
{\left[-72^{\circ}\right]}\end{array}$ & $\begin{array}{c}0.16 \times 10^{-9} \\
{\left[113^{\circ}\right]}\end{array}$ \\
\hline & After control & $\begin{array}{c}0.05 \times 10^{-10} \\
{\left[101^{\circ}\right]}\end{array}$ & $\begin{array}{c}0.03 \times 10^{-10} \\
{\left[117^{\circ}\right]}\end{array}$ & $\begin{array}{c}0.18 \times 10^{-9} \\
{\left[-62^{\circ}\right]}\end{array}$ & $\begin{array}{c}0.06 \times 10^{-9} \\
{\left[-75^{\circ}\right]}\end{array}$ & $\begin{array}{c}0.01 \times 10^{-9} \\
{\left[84^{\circ}\right]}\end{array}$ & $\begin{array}{c}0.02 \times 10^{-9} \\
{\left[-163^{\circ}\right]}\end{array}$ & $\begin{array}{c}0.05 \times 10^{-10} \\
{\left[90^{\circ}\right]}\end{array}$ & $\begin{array}{c}0.21 \times 10^{-9} \\
{\left[-89^{\circ}\right]}\end{array}$ & $\begin{array}{c}0.15 \times 10^{-9} \\
{\left[88^{\circ}\right]}\end{array}$ & $\begin{array}{c}0.10 \times 10^{-9} \\
{\left[123^{\circ}\right]}\end{array}$ \\
\hline \multirow[b]{2}{*}{$(3,1)$} & Before control & $\begin{array}{c}0.01 \times 10^{-10} \\
{\left[124^{\circ}\right]}\end{array}$ & $\begin{array}{c}0.03 \times 10^{-10} \\
{\left[58^{\circ}\right]}\end{array}$ & $\begin{array}{c}0.02 \times 10^{-9} \\
{\left[124^{\circ}\right]}\end{array}$ & $\begin{array}{c}0.01 \times 10^{-9} \\
{\left[110^{\circ}\right]}\end{array}$ & $\begin{array}{c}0.02 \times 10^{-10} \\
{\left[25^{\circ}\right]}\end{array}$ & $\begin{array}{c}0.03 \times 10^{-9} \\
{\left[-59^{\circ}\right]}\end{array}$ & $\begin{array}{c}0.05 \times 10^{-9} \\
{\left[99^{\circ}\right]}\end{array}$ & $\begin{array}{c}0.08 \times 10^{-9} \\
{\left[78^{\circ}\right]}\end{array}$ & $\begin{array}{c}0.39 \times 10^{-9} \\
{\left[105^{\circ}\right]}\end{array}$ & $\begin{array}{c}0.03 \times 10^{-9} \\
{\left[-61^{\circ}\right]}\end{array}$ \\
\hline & After control & $\begin{array}{c}0.06 \times 10^{-10} \\
{\left[98^{\circ}\right]}\end{array}$ & $\begin{array}{c}0.05 \times 10^{-10} \\
{\left[-66^{\circ}\right]} \\
\end{array}$ & $\begin{array}{c}0.02 \times 10^{-9} \\
{\left[127^{\circ}\right]} \\
\end{array}$ & $\begin{array}{c}0.02 \times 10^{-9} \\
{\left[104^{\circ}\right]} \\
\end{array}$ & $\begin{array}{c}0.01 \times 10^{-9} \\
{\left[82^{\circ}\right]}\end{array}$ & $\begin{array}{c}0.04 \times 10^{-9} \\
{\left[-63^{\circ}\right]}\end{array}$ & $\begin{array}{c}0.01 \times 10^{-9} \\
{\left[-96^{\circ}\right]} \\
\end{array}$ & $\begin{array}{c}0.18 \times 10^{-9} \\
{\left[88^{\circ}\right]} \\
\end{array}$ & $\begin{array}{c}0.12 \times 10^{-9} \\
{\left[-95^{\circ}\right]} \\
\end{array}$ & $\begin{array}{c}0.02 \times 10^{-9} \\
{\left[-51^{\circ}\right]}\end{array}$ \\
\hline \multirow{2}{*}{$(2,2)$} & Before control & $\begin{array}{c}0.02 \times 10^{-10} \\
{\left[-52^{\circ}\right]}\end{array}$ & $\begin{array}{c}0.03 \times 10^{-10} \\
{\left[63^{\circ}\right]}\end{array}$ & $\begin{array}{c}0.25 \times 10^{-9} \\
{\left[117^{\circ}\right]}\end{array}$ & $\begin{array}{c}0.16 \times 10^{-9} \\
{\left[107^{\circ}\right]}\end{array}$ & $\begin{array}{c}0.04 \times 10^{-10} \\
{\left[-152^{\circ}\right]}\end{array}$ & $\begin{array}{c}0.38 \times 10^{-9} \\
{\left[-68^{\circ}\right]}\end{array}$ & $\begin{array}{c}0.05 \times 10^{-9} \\
{\left[104^{\circ}\right]}\end{array}$ & $\begin{array}{c}0.19 \times 10^{-9} \\
{\left[81^{\circ}\right]}\end{array}$ & $\begin{array}{c}0.96 \times 10^{-9} \\
{\left[108^{\circ}\right]}\end{array}$ & $\begin{array}{c}0.56 \times 10^{-9} \\
{\left[-69^{\circ}\right]}\end{array}$ \\
\hline & After control & $\begin{array}{c}0.01 \times 10^{-9} \\
{\left[-78^{\circ}\right]}\end{array}$ & $\begin{array}{c}0.06 \times 10^{-10} \\
{\left[-61^{\circ}\right]}\end{array}$ & $\begin{array}{c}0.21 \times 10^{-9} \\
{\left[120^{\circ}\right]}\end{array}$ & $\begin{array}{c}0.23 \times 10^{-9} \\
{\left[102^{\circ}\right]}\end{array}$ & $\begin{array}{c}0.02 \times 10^{-9} \\
{\left[-95^{\circ}\right]}\end{array}$ & $\begin{array}{c}0.47 \times 10^{-9} \\
{\left[-71^{\circ}\right]}\end{array}$ & $\begin{array}{c}0.01 \times 10^{-9} \\
{\left[-91^{\circ}\right]}\end{array}$ & $\begin{array}{c}0.45 \times 10^{-9} \\
{\left[91^{\circ}\right]}\end{array}$ & $\begin{array}{c}0.30 \times 10^{-9} \\
{\left[-92^{\circ}\right]}\end{array}$ & $\begin{array}{c}0.34 \times 10^{-9} \\
{\left[-59^{\circ}\right]}\end{array}$ \\
\hline \multirow{2}{*}{$(3,2)$} & Before control & $\begin{array}{c}0.04 \times 10^{-10} \\
{\left[128^{\circ}\right]}\end{array}$ & $\begin{array}{c}0.01 \times 10^{-9} \\
{\left[-120^{\circ}\right]}\end{array}$ & $\begin{array}{c}0.40 \times 10^{-9} \\
{\left[-63^{\circ}\right]}\end{array}$ & $\begin{array}{c}0.13 \times 10^{-9} \\
{\left[-70^{\circ}\right]}\end{array}$ & $\begin{array}{c}0.09 \times 10^{-10} \\
{\left[27^{\circ}\right]}\end{array}$ & $\begin{array}{c}0.77 \times 10^{-9} \\
{\left[111^{\circ}\right]}\end{array}$ & $\begin{array}{c}0.08 \times 10^{-9} \\
{\left[-75^{\circ}\right]}\end{array}$ & $\begin{array}{c}0.41 \times 10^{-9} \\
{\left[-100^{\circ}\right]}\end{array}$ & $\begin{array}{c}0.22 \times 10^{-8} \\
{\left[-73^{\circ}\right]}\end{array}$ & $\begin{array}{c}0.05 \times 10^{-8} \\
{\left[114^{\circ}\right]}\end{array}$ \\
\hline & After control & $\begin{array}{c}0.02 \times 10^{-9} \\
{\left[102^{\circ}\right]}\end{array}$ & $\begin{array}{c}0.02 \times 10^{-9} \\
{\left[115^{\circ}\right]}\end{array}$ & $\begin{array}{c}0.34 \times 10^{-9} \\
{\left[-59^{\circ}\right]}\end{array}$ & $\begin{array}{c}0.19 \times 10^{-9} \\
{\left[-75^{\circ}\right]}\end{array}$ & $\begin{array}{c}0.05 \times 10^{-9} \\
{\left[83^{\circ}\right]}\end{array}$ & $\begin{array}{c}0.93 \times 10^{-9} \\
{\left[108^{\circ}\right]}\end{array}$ & $\begin{array}{c}0.02 \times 10^{-9} \\
{\left[90^{\circ}\right]}\end{array}$ & $\begin{array}{c}0.96 \times 10^{-9} \\
{\left[-90^{\circ}\right]}\end{array}$ & $\begin{array}{c}0.68 \times 10^{-9} \\
{\left[87^{\circ}\right]}\end{array}$ & $\begin{array}{c}0.31 \times 10^{-9} \\
{\left[124^{\circ}\right]}\end{array}$ \\
\hline
\end{tabular}


Table 6. Cont.

\begin{tabular}{|c|c|c|c|c|c|c|c|c|c|c|c|}
\hline & & \multicolumn{10}{|c|}{ The Energy Contributions from Cavity Modes $(z(i, j) P(i)$, Unit: $\mathrm{m})$} \\
\hline \multirow{2}{*}{\multicolumn{2}{|c|}{ Cavity modes }} & 1 & 2 & 3 & 4 & 5 & 6 & 7 & 8 & 9 & 10 \\
\hline & & $(0,0,0)$ & $(1,0,0)$ & $(0,1,0)$ & $(1,1,0)$ & $(2,0,0)$ & $(2,1,0)$ & $(0,2,0)$ & $(3,0,0)$ & $(1,2,0)$ & $(3,1,0)$ \\
\hline \multicolumn{12}{|c|}{ Case 3} \\
\hline \multirow{2}{*}{$(4,1)$} & Before control & $\begin{array}{c}0.09 \times 10^{-11} \\
{\left[-53^{\circ}\right]}\end{array}$ & $\begin{array}{c}0.05 \times 10^{-10} \\
{\left[-122^{\circ}\right]}\end{array}$ & $\begin{array}{c}0.09 \times 10^{-9} \\
{\left[117^{\circ}\right]}\end{array}$ & $\begin{array}{c}0.08 \times 10^{-9} \\
{\left[106^{\circ}\right]}\end{array}$ & $\begin{array}{c}0.02 \times 10^{-10} \\
{\left[-153^{\circ}\right]}\end{array}$ & $\begin{array}{c}0.14 \times 10^{-9} \\
{\left[-68^{\circ}\right]}\end{array}$ & $\begin{array}{c}0.01 \times 10^{-9} \\
{\left[107^{\circ}\right]}\end{array}$ & $\begin{array}{c}0.28 \times 10^{-9} \\
{\left[78^{\circ}\right]}\end{array}$ & $\begin{array}{c}0.75 \times 10^{-9} \\
{\left[106^{\circ}\right]}\end{array}$ & $\begin{array}{c}0.01 \times 10^{-9} \\
{\left[44^{\circ}\right]}\end{array}$ \\
\hline & After control & $\begin{array}{c}0.04 \times 10^{-10} \\
{\left[-79^{\circ}\right]}\end{array}$ & $\begin{array}{c}0.08 \times 10^{-10} \\
{\left[113^{\circ}\right]}\end{array}$ & $\begin{array}{c}0.08 \times 10^{-9} \\
{\left[120^{\circ}\right]}\end{array}$ & $\begin{array}{c}0.12 \times 10^{-9} \\
{\left[101^{\circ}\right]}\end{array}$ & $\begin{array}{c}0.01 \times 10^{-9} \\
{\left[-97^{\circ}\right]}\end{array}$ & $\begin{array}{c}0.17 \times 10^{-9} \\
{\left[-71^{\circ}\right]}\end{array}$ & $\begin{array}{c}0.03 \times 10^{-9} \\
{\left[-87^{\circ}\right]}\end{array}$ & $\begin{array}{c}0.65 \times 10^{-9} \\
{\left[88^{\circ}\right]}\end{array}$ & $\begin{array}{c}0.24 \times 10^{-9} \\
{\left[-94^{\circ}\right]}\end{array}$ & $\begin{array}{c}0.07 \times 10^{-10} \\
{\left[54^{\circ}\right]}\end{array}$ \\
\hline \multirow{2}{*}{$(1,3)$} & Before control & $\begin{array}{c}0.03 \times 10^{-10} \\
{\left[126^{\circ}\right]}\end{array}$ & $\begin{array}{c}0.06 \times 10^{-10} \\
{\left[-122^{\circ}\right]}\end{array}$ & $\begin{array}{c}0.02 \times 10^{-9} \\
{\left[109^{\circ}\right]}\end{array}$ & $\begin{array}{c}0.08 \times 10^{-10} \\
{\left[-77^{\circ}\right]}\end{array}$ & $\begin{array}{c}0.02 \times 10^{-10} \\
{\left[-152^{\circ}\right]}\end{array}$ & $\begin{array}{c}0.08 \times 10^{-9} \\
{\left[-75^{\circ}\right]}\end{array}$ & $\begin{array}{c}0.14 \times 10^{-9} \\
{\left[-81^{\circ}\right]}\end{array}$ & $\begin{array}{c}0.13 \times 10^{-9} \\
{\left[-104^{\circ}\right]}\end{array}$ & $\begin{array}{c}0.70 \times 10^{-9} \\
{\left[-76^{\circ}\right]}\end{array}$ & $\begin{array}{c}0.02 \times 10^{-9} \\
{\left[-81^{\circ}\right]}\end{array}$ \\
\hline & After control & $\begin{array}{c}0.02 \times 10^{-9} \\
{\left[99^{\circ}\right]} \\
\end{array}$ & $\begin{array}{c}0.01 \times 10^{-9} \\
{\left[113^{\circ}\right]}\end{array}$ & $\begin{array}{c}0.02 \times 10^{-9} \\
{\left[112^{\circ}\right]}\end{array}$ & $\begin{array}{c}0.01 \times 10^{-9} \\
{\left[-82^{\circ}\right]}\end{array}$ & $\begin{array}{c}0.01 \times 10^{-9} \\
{\left[-96^{\circ}\right]}\end{array}$ & $\begin{array}{c}0.10 \times 10^{-9} \\
{\left[-79^{\circ}\right]}\end{array}$ & $\begin{array}{c}0.03 \times 10^{-9} \\
{\left[84^{\circ}\right]}\end{array}$ & $\begin{array}{c}0.31 \times 10^{-9} \\
{\left[-94^{\circ}\right]}\end{array}$ & $\begin{array}{c}0.22 \times 10^{-9} \\
{\left[84^{\circ}\right]}\end{array}$ & $\begin{array}{c}0.01 \times 10^{-9} \\
{\left[-71^{\circ}\right]}\end{array}$ \\
\hline
\end{tabular}




\section{(c) On the resonant frequency of the ribbed plate B}

The exciting frequency is successively chosen as $f=203 \mathrm{~Hz}$ (Case 4) and $f=425 \mathrm{~Hz}$ (Case5) for this analysis. The control mechanisms on these resonant frequencies present the following two patterns. The first pattern is also in accord with that in Section (b), where suppression and rearrangement of the cavity modes work together to suppress the base plate modes. This is validated by the plots in Figure 8 and the data in Table 7 for Case 4 . The second pattern is rearranging the cavity modes to suppress the base plate modes. The cavity modes are all further strengthened, but their energy contributions to each base plate mode cancel each other due to the opposite phase. This is demonstrated by the plots in Figure 8 and the data in Table 7 for Case 5 .

It can be found that the mechanism involved in the orthogonal ribbed case is also different from that in the single ribbed case on the resonant frequency of the ribbed plate B. The first pattern is also a new phenomenon and emerges due to the interlaced coupling relations triggered by the orthogonal two ribs. The single ribbed case only involves the second pattern. However, it is only formally analogous with the mechanism involved in the orthogonal ribbed case, and the control process is distinctly different. More cavity modes are excited here in the controlled condition to participate in the control process, due to the interlaced coupling relations of the orthogonal two ribs.
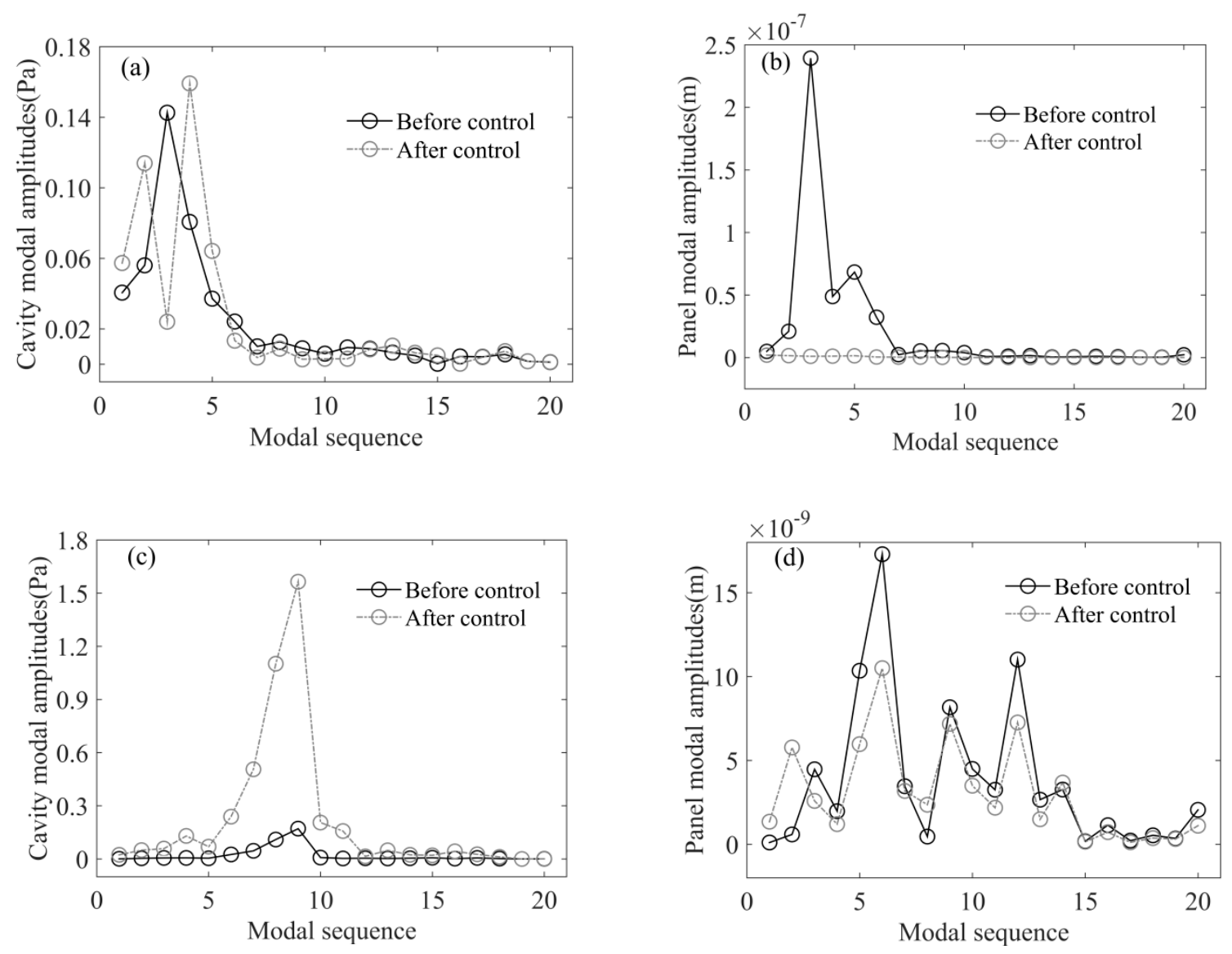

Figure 8. Modal amplitudes of the first twenty modes before and after control when $f=203 \mathrm{~Hz}$ (Case 4), $f=425 \mathrm{~Hz}$ (Case 5). (a,c) (a) Cavity modes for Cases 4, (c) Cavity modes for Cases 5. (b,d) (b) Base plate B modes for Cases 4, (d) Base plate B modes for Cases 5. 
Table 7. The energy contributions of the cavity modes to the base plate B modes.

\begin{tabular}{|c|c|c|c|c|c|c|c|c|c|c|c|}
\hline \multicolumn{12}{|c|}{ The Energy Contributions from Cavity Modes $(z(i, j) P(i)$, Unit: $m)$} \\
\hline \multirow{2}{*}{\multicolumn{2}{|c|}{ Cavity modes }} & 1 & 2 & 3 & 4 & 5 & 6 & 7 & 8 & 9 & 10 \\
\hline & & $(0,0,0)$ & $(1,0,0)$ & $(0,1,0)$ & $(1,1,0)$ & $(2,0,0)$ & $(2,1,0)$ & $(0,2,0)$ & $(3,0,0)$ & $(1,2,0)$ & $(3,1,0)$ \\
\hline \multicolumn{12}{|c|}{ Case 4} \\
\hline \multirow{2}{*}{$(1,2)$} & Before control & $\begin{array}{c}0.01 \times 10^{-6} \\
{\left[-137^{\circ}\right]}\end{array}$ & $\begin{array}{c}0.07 \times 10^{-7} \\
{\left[-130^{\circ}\right]}\end{array}$ & $\begin{array}{c}0.21 \times 10^{-6} \\
{\left[-70^{\circ}\right]}\end{array}$ & $\begin{array}{c}0.02 \times 10^{-6} \\
{\left[-139^{\circ}\right]}\end{array}$ & $\begin{array}{c}0.09 \times 10^{-7} \\
{\left[47^{\circ}\right]}\end{array}$ & & & & & \\
\hline & After control & $\begin{array}{c}0.15 \times 10^{-7} \\
{\left[-140^{\circ}\right]}\end{array}$ & $\begin{array}{c}0.14 \times 10^{-7} \\
{\left[-137^{\circ}\right]}\end{array}$ & $\begin{array}{c}0.36 \times 10^{-7} \\
{\left[38^{\circ}\right]} \\
\end{array}$ & $\begin{array}{c}0.45 \times 10^{-7} \\
{\left[-143^{\circ}\right]}\end{array}$ & $\begin{array}{c}0.15 \times 10^{-7} \\
{\left[41^{\circ}\right]} \\
\end{array}$ & & & & & \\
\hline \multirow{2}{*}{$(3,1)$} & Before control & $\begin{array}{c}0.03 \times 10^{-7} \\
{\left[58^{\circ}\right]}\end{array}$ & $\begin{array}{c}0.01 \times 10^{-7} \\
{\left[22^{\circ}\right]}\end{array}$ & $\begin{array}{c}0.44 \times 10^{-7} \\
{\left[109^{\circ}\right]}\end{array}$ & $\begin{array}{c}0.05 \times 10^{-7} \\
{\left[40^{\circ}\right]}\end{array}$ & $\begin{array}{c}0.02 \times 10^{-7} \\
{\left[-120^{\circ}\right]}\end{array}$ & & & & & \\
\hline & After control & $\begin{array}{c}0.42 \times 10^{-8} \\
{\left[55^{\circ}\right]}\end{array}$ & $\begin{array}{c}0.22 \times 10^{-8} \\
{\left[16^{\circ}\right]}\end{array}$ & $\begin{array}{c}0.75 \times 10^{-8} \\
{\left[-143^{\circ}\right]}\end{array}$ & $\begin{array}{c}0.91 \times 10^{-8} \\
{\left[35^{\circ}\right]}\end{array}$ & $\begin{array}{c}0.38 \times 10^{-8} \\
{\left[-126^{\circ}\right]}\end{array}$ & & & & & \\
\hline \multirow{2}{*}{$(2,2)$} & Before control & $\begin{array}{c}0.03 \times 10^{-7} \\
{\left[-139^{\circ}\right]}\end{array}$ & $\begin{array}{c}0.02 \times 10^{-7} \\
{\left[-124^{\circ}\right]}\end{array}$ & $\begin{array}{c}0.61 \times 10^{-7} \\
{\left[-70^{\circ}\right]}\end{array}$ & $\begin{array}{c}0.07 \times 10^{-7} \\
{\left[-136^{\circ}\right]}\end{array}$ & $\begin{array}{c}0.02 \times 10^{-7} \\
{\left[46^{\circ}\right]}\end{array}$ & & & & & \\
\hline & After control & $\begin{array}{c}0.04 \times 10^{-7} \\
{\left[-142^{\circ}\right]}\end{array}$ & $\begin{array}{c}0.04 \times 10^{-7} \\
{\left[-130^{\circ}\right]}\end{array}$ & $\begin{array}{c}0.10 \times 10^{-7} \\
{\left[38^{\circ}\right]}\end{array}$ & $\begin{array}{c}0.13 \times 10^{-7} \\
{\left[-140^{\circ}\right]}\end{array}$ & $\begin{array}{c}0.04 \times 10^{-7} \\
{\left[41^{\circ}\right]}\end{array}$ & & & & & \\
\hline \multirow[b]{2}{*}{$(3,2)$} & Before control & $\begin{array}{c}0.02 \times 10^{-7} \\
{\left[49^{\circ}\right]}\end{array}$ & $\begin{array}{c}0.08 \times 10^{-8} \\
{\left[38^{\circ}\right]}\end{array}$ & $\begin{array}{c}0.29 \times 10^{-7} \\
{\left[109^{\circ}\right]}\end{array}$ & $\begin{array}{c}0.03 \times 10^{-7} \\
{\left[39^{\circ}\right]}\end{array}$ & $\begin{array}{c}0.01 \times 10^{-7} \\
{\left[-127^{\circ}\right]}\end{array}$ & & & & & \\
\hline & After control & $\begin{array}{c}0.23 \times 10^{-8} \\
{\left[46^{\circ}\right]}\end{array}$ & $\begin{array}{c}0.16 \times 10^{-8} \\
{\left[32^{\circ}\right]}\end{array}$ & $\begin{array}{c}0.49 \times 10^{-8} \\
{\left[-142^{\circ}\right]}\end{array}$ & $\begin{array}{c}0.59 \times 10^{-8} \\
{\left[35^{\circ}\right]}\end{array}$ & $\begin{array}{c}0.22 \times 10^{-8} \\
{\left[-133^{\circ}\right]}\end{array}$ & & & & & \\
\hline \multicolumn{12}{|c|}{$\begin{array}{c}\text { Case } 5 \\
\end{array}$} \\
\hline \multirow{2}{*}{$(2,2)$} & Before control & $\begin{array}{c}0.03 \times 10^{-9} \\
{\left[63^{\circ}\right]}\end{array}$ & $\begin{array}{c}0.08 \times 10^{-9} \\
{\left[-157^{\circ}\right]}\end{array}$ & $\begin{array}{c}0.06 \times 10^{-8} \\
{\left[49^{\circ}\right]}\end{array}$ & $\begin{array}{c}0.03 \times 10^{-8} \\
{\left[-137^{\circ}\right]}\end{array}$ & $\begin{array}{c}0.01 \times 10^{-8} \\
{\left[57^{\circ}\right]}\end{array}$ & $\begin{array}{c}0.14 \times 10^{-8} \\
{\left[74^{\circ}\right]}\end{array}$ & $\begin{array}{c}0.14 \times 10^{-8} \\
{\left[-134^{\circ}\right]}\end{array}$ & $\begin{array}{c}0.52 \times 10^{-8} \\
{\left[0.4^{\circ}\right]}\end{array}$ & $\begin{array}{c}0.74 \times 10^{-8} \\
{\left[42^{\circ}\right]}\end{array}$ & $\begin{array}{c}0.05 \times 10^{-8} \\
{\left[-110^{\circ}\right]}\end{array}$ \\
\hline & After control & $\begin{array}{c}0.07 \times 10^{-8} \\
{\left[63^{\circ}\right]}\end{array}$ & $\begin{array}{c}0.01 \times 10^{-7} \\
{\left[67^{\circ}\right]}\end{array}$ & $\begin{array}{c}0.06 \times 10^{-7} \\
{\left[63^{\circ}\right]}\end{array}$ & $\begin{array}{c}0.06 \times 10^{-7} \\
{\left[-119^{\circ}\right]}\end{array}$ & $\begin{array}{c}0.02 \times 10^{-7} \\
{\left[62^{\circ}\right]}\end{array}$ & $\begin{array}{c}0.13 \times 10^{-7} \\
{\left[66^{\circ}\right]}\end{array}$ & $\begin{array}{c}0.16 \times 10^{-7} \\
{\left[68^{\circ}\right]}\end{array}$ & $\begin{array}{c}0.52 \times 10^{-7} \\
{\left[55^{\circ}\right]}\end{array}$ & $\begin{array}{c}0.68 \times 10^{-7} \\
{\left[-118^{\circ}\right]}\end{array}$ & $\begin{array}{c}0.11 \times 10^{-7} \\
{\left[-119^{\circ}\right]}\end{array}$ \\
\hline \multirow{2}{*}{$(3,2)$} & Before control & $\begin{array}{c}0.05 \times 10^{-9} \\
{\left[-117^{\circ}\right]}\end{array}$ & $\begin{array}{c}0.01 \times 10^{-8} \\
{\left[20^{\circ}\right]}\end{array}$ & $\begin{array}{c}0.10 \times 10^{-8} \\
{\left[-131^{\circ}\right]}\end{array}$ & $\begin{array}{c}0.05 \times 10^{-8} \\
{\left[47^{\circ}\right]}\end{array}$ & $\begin{array}{c}0.02 \times 10^{-8} \\
{\left[-25^{\circ}\right]}\end{array}$ & $\begin{array}{c}0.02 \times 10^{-7} \\
{\left[-106^{\circ}\right]}\end{array}$ & $\begin{array}{c}0.02 \times 10^{-7} \\
{\left[46^{\circ}\right]}\end{array}$ & $\begin{array}{c}0.09 \times 10^{-7} \\
{\left[180^{\circ}\right]}\end{array}$ & $\begin{array}{c}0.12 \times 10^{-7} \\
{\left[-139^{\circ}\right]}\end{array}$ & $\begin{array}{c}0.08 \times 10^{-8} \\
{\left[73^{\circ}\right]}\end{array}$ \\
\hline & After control & $\begin{array}{c}0.01 \times 10^{-7} \\
{\left[-117^{\circ}\right]}\end{array}$ & $\begin{array}{c}0.02 \times 10^{-7} \\
{\left[-116^{\circ}\right]}\end{array}$ & $\begin{array}{c}0.01 \times 10^{-6} \\
{\left[-117^{\circ}\right]}\end{array}$ & $\begin{array}{c}0.01 \times 10^{-6} \\
{\left[65^{\circ}\right]}\end{array}$ & $\begin{array}{c}0.03 \times 10^{-7} \\
{\left[-119^{\circ}\right]}\end{array}$ & $\begin{array}{c}0.02 \times 10^{-6} \\
{\left[-115^{\circ}\right]}\end{array}$ & $\begin{array}{c}0.03 \times 10^{-6} \\
{\left[-112^{\circ}\right]}\end{array}$ & $\begin{array}{c}0.09 \times 10^{-6} \\
{\left[-125^{\circ}\right]}\end{array}$ & $\begin{array}{c}0.11 \times 10^{-6} \\
{\left[61^{\circ}\right]}\end{array}$ & $\begin{array}{c}0.02 \times 10^{-6} \\
{\left[64^{\circ}\right]}\end{array}$ \\
\hline \multirow{2}{*}{$(5,1)$} & Before control & $\begin{array}{c}0.01 \times 10^{-9} \\
{\left[-93^{\circ}\right]}\end{array}$ & $\begin{array}{c}0.03 \times 10^{-9} \\
{\left[23^{\circ}\right]}\end{array}$ & $\begin{array}{c}0.02 \times 10^{-8} \\
{\left[-131^{\circ}\right]}\end{array}$ & $\begin{array}{c}0.09 \times 10^{-9} \\
{\left[44^{\circ}\right]}\end{array}$ & $\begin{array}{c}0.05 \times 10^{-9} \\
{\left[-98^{\circ}\right]}\end{array}$ & $\begin{array}{c}0.05 \times 10^{-8} \\
{\left[-104^{\circ}\right]}\end{array}$ & $\begin{array}{c}0.05 \times 10^{-8} \\
{\left[29^{\circ}\right]}\end{array}$ & $\begin{array}{c}0.17 \times 10^{-8} \\
{\left[179^{\circ}\right]}\end{array}$ & $\begin{array}{c}0.24 \times 10^{-8} \\
{\left[-139^{\circ}\right]}\end{array}$ & $\begin{array}{c}0.02 \times 10^{-8} \\
{\left[70^{\circ}\right]}\end{array}$ \\
\hline & After control & $\begin{array}{c}0.03 \times 10^{-8} \\
{\left[-94^{\circ}\right]}\end{array}$ & $\begin{array}{c}0.04 \times 10^{-8} \\
{\left[-112^{\circ}\right]}\end{array}$ & $\begin{array}{c}0.02 \times 10^{-7} \\
{\left[-117^{\circ}\right]}\end{array}$ & $\begin{array}{c}0.02 \times 10^{-7} \\
{\left[62^{\circ}\right]}\end{array}$ & $\begin{array}{c}0.07 \times 10^{-8} \\
{\left[-92^{\circ}\right]}\end{array}$ & $\begin{array}{c}0.04 \times 10^{-7} \\
{\left[-112^{\circ}\right]}\end{array}$ & $\begin{array}{c}0.05 \times 10^{-7} \\
{\left[-129^{\circ}\right]}\end{array}$ & $\begin{array}{c}0.17 \times 10^{-7} \\
{\left[-126^{\circ}\right]} \\
\end{array}$ & $\begin{array}{c}0.22 \times 10^{-7} \\
{\left[61^{\circ}\right]}\end{array}$ & $\begin{array}{c}0.04 \times 10^{-7} \\
{\left[61^{\circ}\right]}\end{array}$ \\
\hline
\end{tabular}




\section{(d) On the off-resonant frequency}

The control mechanism on the off-resonant frequency mainly involves the pattern similar to tha in Section (b), i.e., the cavity modal suppression and rearrangement suppressing the modes of the base plate $\mathrm{B}$. This is different from that of the single ribbed case, where the rearrangement of the cavity modes rearranges the base plate modes to make it as a weak radiator [23]. The kinetic energy of the radiating ribbed plate is likely to be enhanced in the controlled condition. However, this rarely appears in the orthogonally two ribs stiffened case. The complicated coupling relations and numerous energy transmission paths between the cavity modes and base plate modes guarantee that the base plate modes can always be suppressed only by adjusting several most important cavity modes that have well coupling relations with them. There is no need to further rearrange the base plate modes to achieve sound radiation cancellation [24].

For validating this conclusion, the averaged quadratic velocity of the base plate $\mathrm{B}\left\langle V^{2}\right\rangle$ which represents the kinetic energy of the plate is calculated before and after control, as shown in Figure 9. The averaged quadratic velocity is defined as [25]:

$$
\left\langle V^{2}\right\rangle=\frac{\omega^{2}}{2 A_{b}} \int_{A} w_{b} w_{b}^{\mathrm{H}} \mathrm{d} s
$$

where $\mathrm{H}$ denotes the complex conjugate, and $A_{b}$ is the area of the base plate. $\left\langle V^{2}\right\rangle$ is expressed in $\mathrm{dB}$ referenced to $2.5 \times 10^{-15} \mathrm{~m}^{2} / \mathrm{s}^{2}$. The kinetic energy decreases remarkably after control in entire low frequency band, which validates the conclusion stated above.

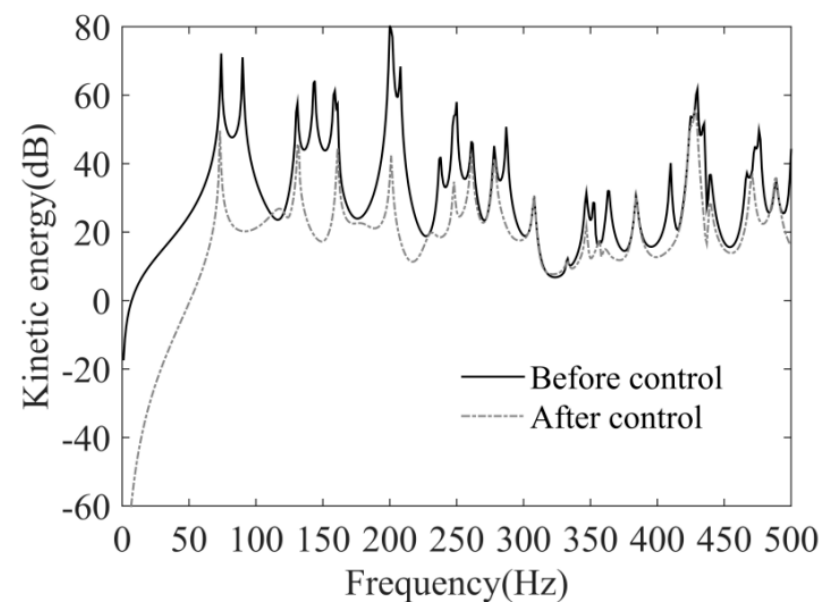

Figure 9. The kinetic energy of the ribbed plate B before and after control.

\section{Conclusions}

This paper developed the investigation on mechanism analysis of active control of sound transmission through orthogonal rib stiffened double-panel structure. The resonant frequencies of the ribbed plate and the displacement of certain points on the ribbed plate B is calculated both by analytical and numerical approach. The results of these methods agree well, which validates the accuracy of the model. Active sound insulation for orthogonal ribbed case is slightly lower than that of the single ribbed case because of the complicated coupling effects of the two ribs. There are three control mechanisms working at different driving frequencies for active control of noise transmission through the orthogonally ribbed double-panel system. The first is suppression of the cavity modes to achieve the suppression of base plate modes. The second involves simultaneous suppression and rearrangement the cavity modes to achieve the suppression of the base plate modes. This is original for orthogonally ribbed case. The third mechanism involves rearrangement of the cavity modes firstly, which results in the suppression of the base plate modes. The first and third pattern are formally analogous with 
these of the single ribbed case, but more cavity and base plate modes participate in the control process. On off-resonant frequency, due to the complicated coupling relations between the cavity and base plate modes, the base plate modes can always be suppressed by appropriately controlling several important cavity modes that couple well with them. Further rearrangement of the base plate modes is not necessary for achieving sound radiation cancellation in such a case. The complicated coupling relations between the cavity and ribbed plate in the orthogonal ribbed case have to be understood deeper, and this issue has to be developed further in ongoing research.

Author Contributions: Conceptualization, methodology, investigation, writing—original draft preparation, X.M.; supervision, K.C.; writing - review and editing, J.X.

Funding: This research was funded by the Project Supported by Natural Science Basic Research Plan in Shaanxi Province of China (Grant No. 2018JQ1025), the National Natural Science Foundation of China (NSFC, Grant No. 51705421), and the Research Funds of the Central Finance (Grant No. MJ-2015-F-044). The APC was funded by the National Natural Science Foundation of China (NSFC, Grant No. 51705421).

Acknowledgments: We are kindly acknowledged the reviewers for their valuable suggestions and English corrections for improving the quality of this article.

Conflicts of Interest: The authors declare no conflict of interest.

\section{References}

1. Dozio, L.; Ricciardi, M. Free vibration analysis of ribbed plates by a combined analytical-numerical method. J. Sound Vib. 2009, 319, 681-697. [CrossRef]

2. Gardonio, P.; Elliott, S.J. Active control of structure-borne and airborne sound transmission through double panel. J. Aircr. 1999, 36, 1023-1032. [CrossRef]

3. Carneal, J.P.; Fuller, C.R. Active structural acoustic control of noise transmission through double panel systems. AIAA J. 1995, 33, 618-623. [CrossRef]

4. Sas, P.; Bao, C.; Augusztinovicz, F. Active control of sound transmission through a double panel partition. J. Sound Vib. 1995, 180, 609-625. [CrossRef]

5. Pan, J.; Bao, C. Analytical study of different approaches for active control of sound transmission through double walls. J. Acoust. Soc. Am. 1998, 103, 1916-1922. [CrossRef]

6. Pan, X.; Sutton, T.J.; Elliott, S.J. Active control of sound transmission through a double-leaf partition by volume velocity cancellation. J. Acoust. Soc. Am. 1998, 104, 2828-2835. [CrossRef]

7. Bao, C.; Pan, J. Experimental study of different approaches for active control of sound transmission through double walls. J. Acoust. Soc. Am. 1997, 102, 1664-1670. [CrossRef]

8. Ma, X.; Chen, K.; Ding, S. Physical mechanism of active control of sound transmission through rib stiffened double-panel structure. J. Sound Vib. 2016, 371, 2-18. [CrossRef]

9. Lin, T. A study of modal characteristics and the control mechanism of finite periodic and irregular ribbed plates. J. Acoust. Soc. Am. 2008, 123, 729-737. [CrossRef]

10. Chiba, M.; Yoshida, I. Free vibration of a rectangular plat-beam coupled system. J. Sound Vib. 1996, 194, 49-65. [CrossRef]

11. Asku, G.; Ali, R. Free vibration analysis of stiffened plates using finite difference method. J. Sound Vib. 1976, $48,15-25$.

12. Mercer, C.A.; Seavey, M.C. Prediction of natural frequencies and normal modes of skin-stringer panel rows. J. Sound Vib. 1967, 6, 149-162. [CrossRef]

13. Zeng, H.; Bert, C.W. A differential quadrature analysis of vibration for rectangular stiffened plates. J. Sound Vib. 2001, 241, 247-252. [CrossRef]

14. Remillieux, M.C.; Burdisso, R.A. Vibro-acoustic response of an infinite, rib-stiffened, thick-plate assembly using finite-element analysis. J. Acoust. Soc. Am. 2012, 132, EL36-EL42. [CrossRef]

15. Lin, T. An analytical and experimental study of the vibration response of a clamped ribbed plate. J. Sound Vib. 2012, 331, 902-913. [CrossRef]

16. Xin, F.X.; Lu, T.J. Transmission loss of orthogonally rib-stiffened double-panel structures with cavity absorption. J. Acoust. Soc. Am. 2011, 129, 1919-1934. [CrossRef] [PubMed] 
17. Lin, T.; Pan, J. A closed form solution for the dynamic response of finite ribbed plates. J. Acoust. Soc. Am. 2006, 119, 917-925. [CrossRef]

18. Ma, X.; Chen, K.; Ding, S. Some physical insights for active control of sound radiated from a clamped ribbed plate. Appl. Acoust. 2015, 99, 1-7. [CrossRef]

19. Li, Y.Y.; Cheng, L. Mechanisms of active control of sound transmission through a linked double-wall system into an acoustic cavity. Appl. Acoust. 2008, 69, 614-623. [CrossRef]

20. Pan, J.; Hansen, C.H.; Bies, D.A. Active control of noise transmission through a panel into a cavity: I. Analytical study. J. Acoust. Soc. Am. 1990, 87, 2098-2108. [CrossRef]

21. Pan, J.; Hansen, C.H. Active control of noise transmission through a panel into a cavity. II. Experimental study. J. Acoust. Soc. Am. 1991, 90, 1488-1492. [CrossRef]

22. Carneal, J.P.; Fuller, C.R. An analytical and experimental investigation of active structural acoustic control of noise transmission through double panel systems. J. Sound Vib. 2004, 272, 749-771. [CrossRef]

23. Johnson, M.E.; Elliott, S.J. Active control of sound radiation using volume velocity cancellation. J. Acoust. Soc. Am. 1995, 98, 2174-2186. [CrossRef]

24. Sanada, A.; Tanaka, N. Theoretical and experimental study on active sound transmission control based on single structural mode actuation using point actuators. J. Acoust. Soc. Am. 2012, 132, 767-778. [CrossRef] [PubMed]

25. Cheng, L.; Li, Y.Y.; Gao, J.X. Energy transmission in a mechanically-linked double-wall structure coupled to an acoustic enclosure. J. Acoust. Soc. Am. 2005, 117, 2742-2751. [CrossRef] [PubMed]

(C) 2019 by the authors. Licensee MDPI, Basel, Switzerland. This article is an open access article distributed under the terms and conditions of the Creative Commons Attribution (CC BY) license (http://creativecommons.org/licenses/by/4.0/). 